\title{
DOCUMENTO
}

\section{Sanar un mundo herido}

\section{Secretariado para la Justicia Social y la Ecología, de la Com- pañía de Jesús}

\section{Presentación}

Este informe ha aparecido íntegro en la versión electrónica de la revista Promotio iustititae $\mathrm{n}^{\circ} 106(2011 / 2)$. Aquí ofrecemos un extracto de la parte introductoria, precedido de dos comentarios introductorios debidos a Mayte Vizcaino y a Leandro Sequeiros que ayudan a contextualizar el documento.

\section{Un proceso de toma de conciencia y de compromiso de la ciudadanía}

\section{Mayte Vizcaíno Callejón'}

El Informe Sanar un mundo herido, publicado por el Secretariado de la Compañía de Jesús para la Justicia Social y la Ecología, es un trabajo sobre un tema de gran actualidad y de importancia capital en la promoción de la justicia social.

Nuestra sociedad es consciente de que vivimos en "un mundo herido". La Compañía de Jesús, con diferentes motivaciones, quiso involucrarse en este problema y

\footnotetext{
${ }^{1}$ Fundación eteA para el desarrollo y la cooperación, Córdoba.
} 
saber más sobre las causas y consecuencias del comportamiento humano hacia el medio ambiente. En 1999 publicó el documento Un mundo roto. Aquel trabajo de hace ya más de una década es la base del nuevo compromiso y posicionamiento jesuita plasmado ahora en Sanar un mundo herido.

En la encrucijada medioambiental y social en que nos encontramos, no puedo sino valorar positivamente la iniciativa jesuita de crear una "Task Force", o Grupo de Trabajo, sobre ecología. Esta decisión nos coloca a la vanguardia de las organizaciones que luchan por la justicia. Supone también un compromiso con un problema en el que todos estamos implicados directamente y cuyas consecuencias sufren principalmente las personas que se encuentran en situación de pobreza y vulnerabilidad.

Este documento tiene por tanto a sus espaldas el trabajo de muchas personas: expertos algunos en diferentes materias y concienciados todos con la necesidad de saber para entender y para actuar, concienciados con la necesidad de coherencia en nuestra forma de vida para que las generaciones futuras puedan vivir y disfrutar en esta misma casa llamada Tierra. Es necesario entender que nuestro planeta, en el que ya habitamos siete mil millones de seres humanos, ha llegado a un punto en el que cambiar de actitud es imprescindible. Tenemos que orientar de nuevo nuestra forma de desarrollo si queremos que éste sea, de verdad, humano y sostenible, englobando los conceptos de ecológico, económico y social, y situando a la persona en el centro del proceso.

El Informe Sanar un mundo herido reitera la existencia del vínculo entre medio ambiente y pobreza a través de un contenido muy bien estructurado que parte de un análisis de la situación en las diferentes regiones del mundo y define la posición jesuita desde la reconciliación con la creación.

Es destacable el enfoque multidimensional con el que este documento analiza el problema medioambiental desde la dimensión de la fe, que incluye la promoción de la justicia y considera parte de ellas el diálogo con las diferentes culturas y religiones. Este enfoque consigue abarcar el problema desde una perspectiva amplia y de compromiso personal.

En el contexto jesuita en que se mueve el documento, es ineludible la referencia a una llamada a la falta de valores o de espiritualidad, como base de la situación medioambiental actual. El documento recuerda convenientemente que la mayor parte de los problemas medioambientales actuales son generados por la acción humana. También resalta la existencia de las cada vez más grandes diferencias 
de ingresos entre ricos y pobres y la evolución hacia una sociedad donde impera un modelo económico impulsado por un consumismo creciente que desprecia los costes del deterioro ecológico. Es por tanto una cuestión de justicia, no de solidaridad, la que debe primar. Esta concepción supone la relación existente entre la crisis ecológica y la promoción de la justicia. No son por tanto baldías las llamadas hacia una asunción de nuestra responsabilidad y de las consecuencias de nuestros hábitos.

Como apoyo a esta toma de conciencia, los miembros del Grupo de Trabajo proponen, hacia el fin del documento, una serie de recomendaciones que promueven el trabajo en red, la actuación desde la raíz del problema y que tratan de involucrar a todos. Inspiradas en los valores cristianos, estas recomendaciones ayudan a diseñar un nuevo modo de actuar de la Compañía, a través de una autoconciencia del impacto de nuestras acciones en la vida de los demás y en especial, por su vulnerabilidad, en la de los más pobres. Se recuerda y refuerza así que nuestro modo de vida, nuestras acciones diarias son "acciones locales con consecuencias globales" y con mayor impacto sobre los más desfavorecidos.

En este proceso de toma de conciencia y de lucha por una ciudadanía comprometida, no hay que olvidar un componente esencial hasta ahora ausente: la voluntad política para abordar de forma integral esta crisis ecológica es fundamental... Sin verdadera voluntad, la promoción de la justicia y la lucha contra el deterioro medioambiental son inútiles. Así mismo, la importancia de la sociedad civil para generar conciencia y motivar el cambio de modelo es indiscutible, pero sin un poder público que avance también en esta dirección, la ciudadanía se enfrenta a muchos más obstáculos.

Terminan estas palabras con el optimismo vislumbradas en el Informe Sanar un mundo herido, al saber que no estamos solos, que contamos con el apoyo y el compromiso de numerosos movimientos sociales, culturales y religiosos que ya trabajan en ecología. Invito a quienes se animen a iniciar o profundizar por esta senda, a que unan sus esfuerzos colaborando con aquéllos y aprendan de su experiencia. 